\title{
Networks of Meaning: Communication Trajectories in Social Sciences and Humanities. (Sketch of a research problem)
}

\author{
Nombre: Gabriel Vélez-Cuartas \\ Afiliación: Departamento de Sociología. Grupo de Investigación Redes y Actores Sociales \\ Facultad de Ciencias Sociales y Humanas. Universidad de Antioquia. Colombia
}

Dirección electrónica: gabrie/velezcuartas@yahoo.com.mx

\begin{abstract}
Resumen
Las redes de sentido son una aproximación metodológica para ordenar, condensar y agrupar diferentes textos de la ciencia a partir de sus aportaciones, contribuciones y trayectorias comunes. Las herramientas pueden describirse metafóricamente como un cedazo que filtra los textos y los ordena según su sentido temático compartido. Para ello utiliza herramientas provenientes de la cienciometría, el análisis de redes y el análisis documental. Su propósito básico es construir una alternativa de análisis de la producción científica que permita observar otros aspectos de ella como los procesos de consolidación científica en la construcción de respuestas a ciertos temas, hacer visibles las comunidades (no sólo los autores prestigiosos) que hacen posible la construcción de respuestas académicas y científicas y dar cuenta de lo que es conocido en un territorio específico para dar respuesta a sus problemáticas. Aquí se problematize la situación de las ciencias sociales y humanidades a la luz de este modelo.
\end{abstract}

\begin{abstract}
The model of Networks of Meaning is useful for ordering and grouping different texts of science according to their contributions and shared trajectories. The tools used can be described metaphorically as a sieve used to filter texts according to their shared meaning. The model uses tools from scientometrics, network analysis and documentary analysis. Our purpose is presenting an alternative analytical model for observing the dynamics of scientific production for example: paths and trajectories in contributions to solve different problems; not only researchers but communities of researchers that built together different answers; and to know who knows what and where in a specific territory. This model is applied to social sciences and humanities. Here is problematized the situation of social sciences and humanities according to the model.
\end{abstract}

\section{Introduction}

The idea of scientific impact related to community acceptance has been central to scientometric studies and descriptions of science. The introduction of citation impact (i.e. JCR from ISI Thompson) allowed valuing science developments. It was useful but not enough to make assertions about the globality of science. Another set of questions has to be asked to explore the globality of science in regional scientific, social and economic development: How are emerging scientific communities in regional spaces? What kinds of problems and solutions have been proposed? What institutions are making contributions in which themes? 
Número 1, Noviembre 2013. No 02/04. ISSN: 2014-5993

In this context, social sciences and humanities play an important role to understand social and cultural phenomena. Looking their developments only from a scientometric perspective does not allow creating an accurate representation of their visibility and their contributions within specific territories. This research proposes to deal with visibility problems starting on these new questions about scientific development and its relationship with society.

Measuring the impact of social sciences and humanities produced by academic units -such as Social Sciences and Humanities Faculties- is relevant to describe scientific developments and knowledge available to society. There is research on sociology of science about these issues -i.e. Robert K Merton (1979), Karin Knorr-Cetina (2005), Bruno Latour (1999), Pierre Bourdieu (2001), etc. However there is a lack of quantitative models to describe these dynamics, except for scientometrics. Scientometrics most common models of science are related only to citation impact (i.e. JCR, Scopus rankings, etc.). Moreover, there is a lack of models in other conceptual fields unobserved by scientometrics and information available about how regional research contributes to social sciences and humanities ${ }^{1}$. There are no systemic models on mapping scientific contributions ${ }^{2}$; illustrating levels of solidness in formation of academic communities; describing successful field strategies to reach visibility and prestige inside different knowledge areas and disciplines; and following trajectories of scientific problems and solutions expressed to broad audiences.

In addition to the lack of quantitative models, there is a lack of information. Social Sciences have not had the same visibility than other sciences in rankings and scores of impact (Archambault \& Lariviere, 2010). More than a decade ago, Glänzel \& Schoepflin (1999) pointed out that the stark contrast between the many papers about Immunology $(23,396)$ available in ISI Thompson and the few $(3,695)$ on Sociology. More recently, Rodríguez Yunta (2010) found strong differences in the number of academic journals not only between social sciences and natural sciences but also between regions and countries: only $4.3 \%$ of journals in ISI Thompson databases are from Spanish and Portuguese speaking countries. In a recent research, we observed similar differences between Social Sciences and Health Sciences

\footnotetext{
${ }^{1}$ Scientometrics has developed some quantitative models to measure impact. Those models expose and describe prestige and relevance of articles in a structure. For example: co-citation analysis, collaboration analysis and citation impact. Nevertheless they are evaluating science only based on relevance and prestige. They are only two of many possible categories.

${ }^{2}$ Loet Leydesdorff (2001) has worked on developing this kind of models especially to resolve problems of visibility in science, different from questions made in this project. A revision of his work will be useful to complement some statements exposed here.
} 
Número 1, Noviembre 2013. No 02/04. ISSN: 2014-5993

production in Colombia. For every ten articles on Health Sciences there was only one focused on Social Sciences (Vélez Cuartas, Ramirez Ruiz \& Aristizábal, 2013).

Within this project, scientific contributions, communities, field strategies and dissemination of science are understood as trajectories. Here, a trajectory could be defined in a wide sense as the distribution of communications in time (for example: articles about the same subject published in different years). Communications are linked by elements such as concepts indicating contributions, clusters of references that articulate colleges, revered articles signalling prestige, and several forms of messages to disseminate results to different audiences. These elements allow grouping and distributing communications as temporal interconnected events. These interconnections can be understood as trajectories when forms of communication through these elements are expressed in structural forms. Then, how is it possible to map trajectories of scientific communications that use recursive elements not only to present outputs to their peers but also to other communities and audiences? The challenge is to model the evolution of communication in social sciences and humanities as differentiated scientific forms. This project proposes applying a combination of system and network models to represent the expansion of regional social sciences and humanities, using a model that I have called Networks of Meaning.

\section{Research question}

Is it possible to measure the impact of social science and humanities through the model of networks of meaning? If it is, then what is the impact of social sciences and humanities in the development of scientific knowledge in a region?

\section{Theoretical Framework}

This research proposes that is possible to map accumulated scientific knowledge to describe the ability to solve problems within a territory or an organization. It makes a distinction between communications circulating as general expectations and communications produced in a specific territory or organization. Maps of accumulated knowledge allow observing partial conditionalities $^{3}$ that shape actions and decision-making processes. Here, the accumulated knowledge can be metaphorically understood as a ceiling. That is, an artificial border between the sky and the ground. The ground is the territory; the sky is the world as the horizon of meaning. Thus, the networks of meaning are the ceiling to describe actual possibilities of solving problems from a social sciences and humanities perspective within a regional space.

\footnotetext{
${ }^{3}$ It is important to clarify that this kind of maps are partial representations of communication processes. These partial representations do not describe all communications available in a social system. However they can describe partial forms of communication linked to space such as models for uncertainty processing.
} 
Número 1, Noviembre 2013. No 02/04. ISSN: 2014-5993

While the networks of meaning would not include all problem solving possibilities within a science system, this kind of maps would actually reflect the 'solutions at hand'.

\subsection{Scientific communications and their multiple structural couplings: Text as communication events}

Niklas Luhmann (1996) understands science as a social system. Systems can be observed as forms of communications. The broadest form of science allows distinguishing in a scientific way those assertions that could be considered as truth from those that could not. In science, concepts are central to understand the mechanisms to build a truthful argument. Simultaneously, concepts allow specifying three things at once: the selected objects or events and their characteristics (theory); procedures describing or explaining the object and its characteristics (methodology); and the horizon of meaning -whether it is related with the event or not- in which the concepts point out some aspect of reality (limitationalität ${ }^{4}$ ) (Luhmann, 1996).

Moreover, concepts need sentences to specify their meaning. Groups of sentences could be seen as arguments located in sections, articles and journals (Leydesdorff, 2001). These arguments cluster all assertions regardless they are understood as truthful or not. The system operates linking communications or arguments through time considering ${ }^{5}$ whether they are truth or not. This process makes that solutions (past theories and methodologies) become new problems arising from the use of past theories and methodologies to explain observed phenomena (Luhmann, 1996).

Arguments need other arguments. This is what Luhmann calls remissions networks (Luhmann, 1996: 280). It means that a text as a communication is connected with other texts. Luhmann argues that communications use three kinds of resources to link arguments with other arguments. These resources are: (1) reputation of authors, institutions or publications; (2) specialisation of arguments that could be identified within a discipline; and (3) further clarification of statements (Luhmann, 1996: 316-317). These three kinds of resources in texts make possible observing the emergence of two distinctions within communications (Luhmann, 1996, 2007): problem/solution and redundancy/variety/stabilization.

A problem is proposed in terms of arguments. A complete argument proposes a solution, and it can be problematized again -as a kind of method near to Karl Popper's falsacionism. In this

4 Luhmann proposes that limitationalität is a continuous function of theories and methodologies in science system (it has the same function of god in the religious system or scarcity in the economic one).

${ }^{5}$ Truthful arguments are based on prestigious researchers cited, correction of statements suggested by peers, publishing house prestige, specialization of arguments, etc. 
Número 1, Noviembre 2013. No 02/04. ISSN: 2014-5993

sense, texts (that contain arguments) are linked through problems and solutions. These processes can be defined as recursions that need time. For instance, a text needs time to be cited (be selected) for other texts. Each of those selections (i.e. citing, correcting) is a combination of past events in a new arrangement that produces a new event. This new event simultaneously operates through the following distinctions: redundancy -a repetition of elements from past communications-, variations -new arrangements of resources integrated in argumentation- and stabilizations -homeostasis or form retention. If communication is understood in a scientific way, then recursion would guarantee the boundaries of what can and what cannot be said scientifically. In other words, communication occurs within a closed system.

Operationally closed systems are understood as forms of differentiation with their own rules of meaning. A system is closed when:

1) All its components, events or communications operate referring to themselves. For instance, an event needs references to past events addressing the same issues but in a different way (self-reference).

2) All the events are connected in a structure. This structure should have the capacity to generate enough synergy to influence future events in accordance to itself (selforganization).

3) All the events are a reproduction or variation of statements from same structure (selfproduction).

The dissolution of a system occurs when there is a lack of redundancy or variation. Thus linkages between communications disappear.

Nevertheless, systems shift and do not disappear when a scientific communication is expressed through forms of educational speech, political rhetoric or aesthetic performance. In other words, scientific contributions accommodate themselves to other general forms of communication. Structural couplings configure audiences, but more importantly they build new forms of communication. In addition to scientific papers, there are also but also patents, models, technical reports for consultancy, elementary texts books, magazine articles, teaching materials, performances in the field of arts and humanities, musical scores from ethnological research in ancient communities and so on. Thus it is possible to speak about structural couplings within education, politics, economy, organization etc.

The distinction problem/solution in a structural coupling should develop a new system of remissions that modifies their network of references. In order to generate new forms of 
Número 1, Noviembre 2013. No 02/04. ISSN: 2014-5993

meaning these references are modified. However they keep some elements that aloud to understand the modified communication as the result of a scientific process. For instance teaching material explaining the law of gravity should use pedagogical tools to explain a complicated concept from physics in a simple way without losing its scientific content. Thus in order to be understood in new terms it should modify its style, semantic resources (i.e. use of many examples), and text structure (i.e. different emphasis).

\subsection{Networks and systems coupling.}

The main theoretical assumption of this project is that networks can observe systems. In this project the model of networks of meaning will be complemented by Dirk Beacker's theory of form (2013). For this purpose I propose to expand the concept of form by introducing to structural concepts related to networks: Aggregation ${ }^{6}$ and trajectories. On the one hand form could be understood through aggregation processes. On the other hand trajectories can be seen as forms in time.

As described before, the network of references as metaphor is a key concept in Luhmann description of a dynamic system. This concept can be empirically understood as a process of organization where a communication event re-organizes fragments from past events in new forms. This process happens not only when a bibliographic reference appears in a text but also when several texts use the same concept, affiliations, languages, sources and all possible sorts of bibliographic token within a group of texts. If a communication links together another communication, then it is possible to affirm that expectations about a scientific subject increase as well as knowledge available ${ }^{7}$. Meaning is more than an attribution from consciousness to an event. Meaning is a medium that allows forms of organization which are visible in arrangements of elements that represent something. Thus, forms can be tracked on communication events as patterns.

6 "By an aggregate (Menge) we are to understand any collection into a whole (Zusammenfassug zu ienem Gazen) $M$ of definite and separate objects $m$ of our intuition or though. These objects are called elements of M". (Cantor, 1915: 85). Aggregate is not a term used by mathematicians to describe this operations today, instead of set that is most commonly accepted. Nevertheless in computer science the term is kept to describe a special function to group multiple rows on certain criteria to form a single value of more significant meaning. In this research we adopt this term to emphasize on the operation of grouping under a criterion that it's imposed by the system formed on distinctions. Last one assumption is proposed here as the path to couple network and system traditions.

${ }^{7}$ Knowledge available is the same idea of Luhmann talking about knowledge as an expectation not actualized in an event of communication. 
Número 1, Noviembre 2013. No 02/04. ISSN: 2014-5993

The concept of networks of references suggests that social systems have structural properties. According to Luhmann (1992: 259-260), meaning has some structural features that could be used for analytical purposes. Some of these features are: meaning operates by shifting from an unstructured complexity (uncertain meaning) to a structured one (specified meaning); a structure defines the total number of bonds allowed by the system; the interdependencies are given by means of selections, and they operate as limits for future selections; invariability of an structure operates as stabilization, in other words invariability is temporal, according to the system's arrangements (self-organization).

In this context, structure and system are compatible concepts. Then it could be said that network analysis can be proposed as a methodology to study systems. This means that the definition of network should be expanded to explain self-organization and introduce events of communication as structural elements. This task is difficult but not impossible. It is a transit from a metaphor -network of references- to an empirical understanding of network objects. There is a theoretical problem in putting networks and systems together. While a system describes functions, operations, integrations and encodings; a network depicts structures, hierarchies, exchanges and flows.

The traditional network studies are rooted on classical structuralism, structural-functionalism and interaction theories. Basically, the concept of individual can be understood from this perspective as someone who plays a role-status inside a structure composed by relations that determine his behaviour (Wellman, 1988; Nadel, 1957). In network analysis, an individual is represented as a vertex, and exchanges are depicted as ties between vertices. Depending on the underlying sociological theory used, definitions about individuals and linkages can change. However in all cases, the strong association between the concepts of actors and structures make difficult to use the concept of network outside of a subject-structure relationship.

Nevertheless, Harrison White developed some interesting approaches to social systems theory through social network analysis. From netdoms to institutions, White's concept of communication associated with interaction is the natural path for Luhmannian theory of communication on interaction. White et al argued: "the meaning horizon usually sees network locality, configuration of expectations, as neighbourhood star. Correlatively, communication also characterizes and is characterized by immediate context in domain of theme in that horizon." (White et al, 2007: 549). Undoubtedly, their networked interpretation of horizon of meaning is very helpful to understand the crystallization of communication. Nevertheless, according to Luhmann, communication cannot be determined by interactions -or acts of 
Número 1, Noviembre 2013. No 02/04. ISSN: 2014-5993

utterance $^{8}$ guided by an understanding (White et al, 2007: 547). Communication is an operation, a horizon of meaning (Luhmann, 1995) understood as expectations for conscience, organizations, interactions or society in general. White represents through netdomains the formation of expectations matched with exchanges and interaction structures. This research aims to map these expectations not their crystallization.

If we expand the scope of underlying sociological theories, it is possible to see a potential horizon of applications. In recent years, theories of actor-network (ANT), pragmatics and semantics began to apply network procedures to understand social dynamics through networks of texts and other kind of non-human entities. For instance, ANT attributes agency to entities and understands power as function of agency (i.e. technological analysis from ANT); and semantic networks depict language organization and emergencies of meaning through words positions in a structure of phrases.

Luhmann (1996: 280) uses the term networks of references to describe the distinctions between redundancy, variation and stabilization within a system structure. These distinctions suppose the existence of paths of communications events. The distinctions -these and the others presented before- use recursions to maintain their form and specify uncertainty. If each recursion is a new communication event clustered to other events, then every recursion could represent fragments of one or more trajectories. Baecker (2013) represents this operation in his theory of form applied to Shannon and Weaver Mathematical Theory of Communication Model.

\footnotetext{
${ }^{8}$ More precisely, "Utterance is guided by anticipations of the reactions of the others, and not only by the expected further current of communicative, but also by impacts of the utterance on future cooperations and transactions. These expectations continue, as pointed out earlier, to be negotiated and altered through events in situations. The act of utterance is thus also itself guided by an understanding of the social situation, in addition to the constraints in the communications, well spelled out by Luhmann." (White, Fuhse, Thiemann \& Buchholz, 2007: 547). Utterance and Understanding from a luhmannian perspective cannot be described as acts, they are selections of communication. As selections, they only can be understood as recursive distinctions. Objects are different: communication as an act has a long path already done under the name of communication networks -Everett Rogers (1981) and all their colleagues and students as well reputed academics as Noshir Contractor (2003) and others. Perhaps the most elaborated and complex theory of communication networks is presented by White and their colleagues, nevertheless they cannot replace the concept of communication as an act. If we translate this into metaphors we could say that Luhmann describes the sky and White the process of formation of clouds. We have to remember that sky is not only composed by clouds and is more extensive than the clouds themselves.
} 


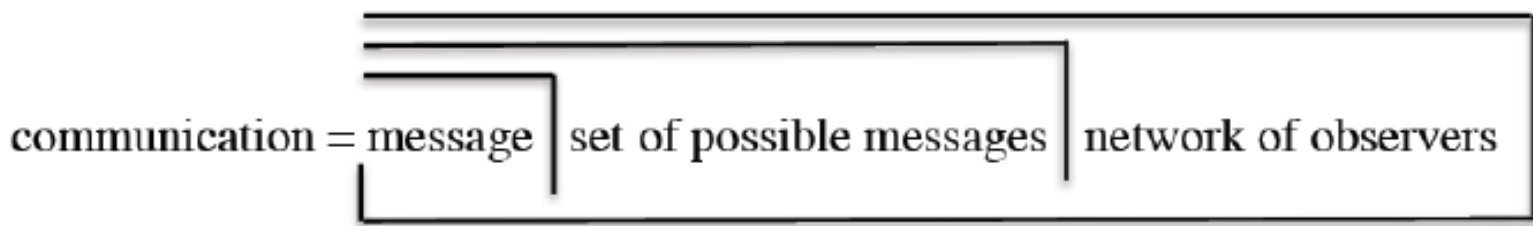

Figure 1. Shannon and Weaver's model and its reconstruction as a selection model. Source: Baecker D (2013: 98)

In figure 1, from the inside to the outside of the model is possible to understand specification of meaning. Each boundary establishes a ceiling to meaning. A message is selected from a set of possible messages shaped by science code and distinguished from other forms of communication in society. This Russian Doll mechanism establishes boundaries of possibilities for forms of communication and for organization and arrangements of structure. The network of observers aggregates elements by doing a re-entry in the system (Baecker, 2013: 98). Each new re-entry increasingly helps to specify the meaning of each distinction through new communication events. In words of Spencer Brown (1977) recursions create time in a distinction (see also Varela, 1977), in communications, meaning. In figure 1, the network of observers could be interpreted as codified communication systems that shape the form of messages and makes possible the emergence of understanding. In figure 2, this interpretation is represented as an equation for scientific communication:

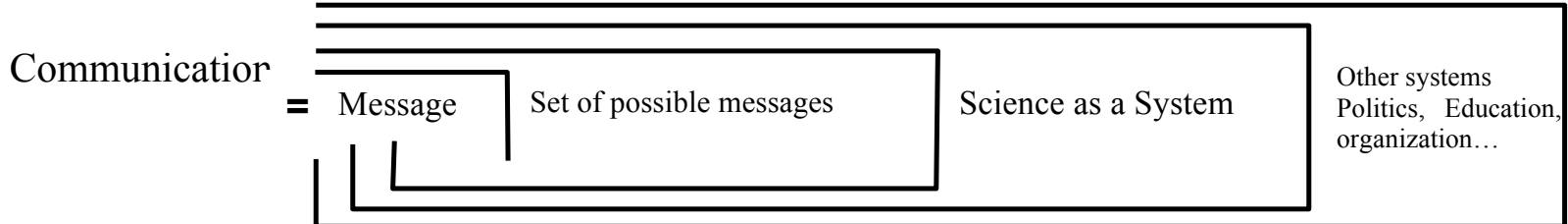

Figure 2. Distinctions of Science as a System

In figure 2, the model is explained from the inside to the outside in terms of recursions. The first recursion occurs when new communication events emerge and preserve the form of previous events. The second recursion diminishes the uncertainty of meaning when other texts use elements of previous texts and new sets of communications emerge. This recursion is made of processes of evaluation and validation, visibility through citation, production of new communications in congresses, etc. Form is modelled as a mud vessel by aggregation of new events. The third recursion is structural coupling. Once communication reaches a scientific form it can be matched with other systems in society. 
Número 1, Noviembre 2013. No 02/04. ISSN: 2014-5993

Empirically, those re-entries or recursions are linked through marks, tokens or signs that appear in communications when different texts use the same concepts, sources of publishing, or/and they are created by same author(s), between other bibliographic elements. The copresence of these elements can be represented as linkages between communications in form of a network. The Aggregation of these elements is another form to represent distinctions. In this form, recursions are distributed on several matrices and represented on graphs as networks of communications. Those representations add reflexivity to the own system.

Time is essential in this process. The stabilization of communications occurs through linked events where ties are co-presence of different elements as concepts, references, affiliations, publishing houses or journals, etc. The form is shaped by aggregation of these elements in networks of communication events. Aggregation means that communication events distributed in a matrix as rows can be grouped by distinctions when they share common elements (as explained before). If we have several common elements (i.e. concepts, specialties and references) it is possible to build a three-dimensional (see figure 3) matrix where communication events are arranged in rows ( $y$ axe in a matrix) and elements are distributed in columns (within $x$ and $z$ axes in a matrix). Graphs represent matrices as shown in figure 4.

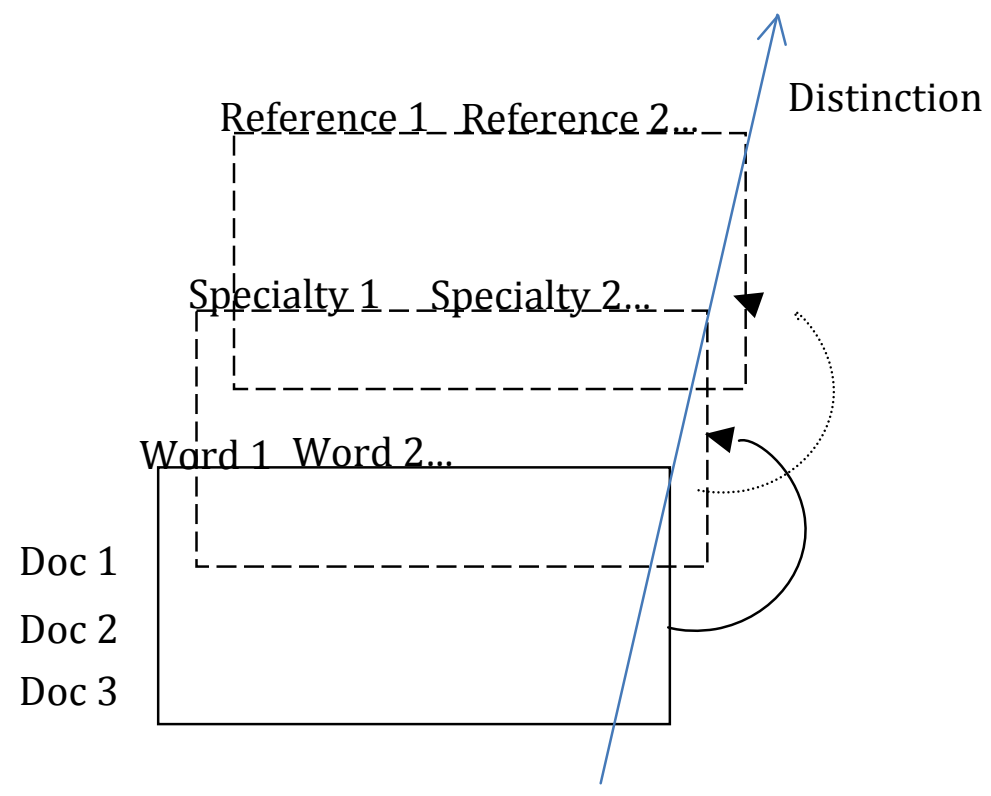

Figure 3. Distinction as a three-dimensional matrix. 
Número 1, Noviembre 2013. No 02/04. ISSN: 2014-5993

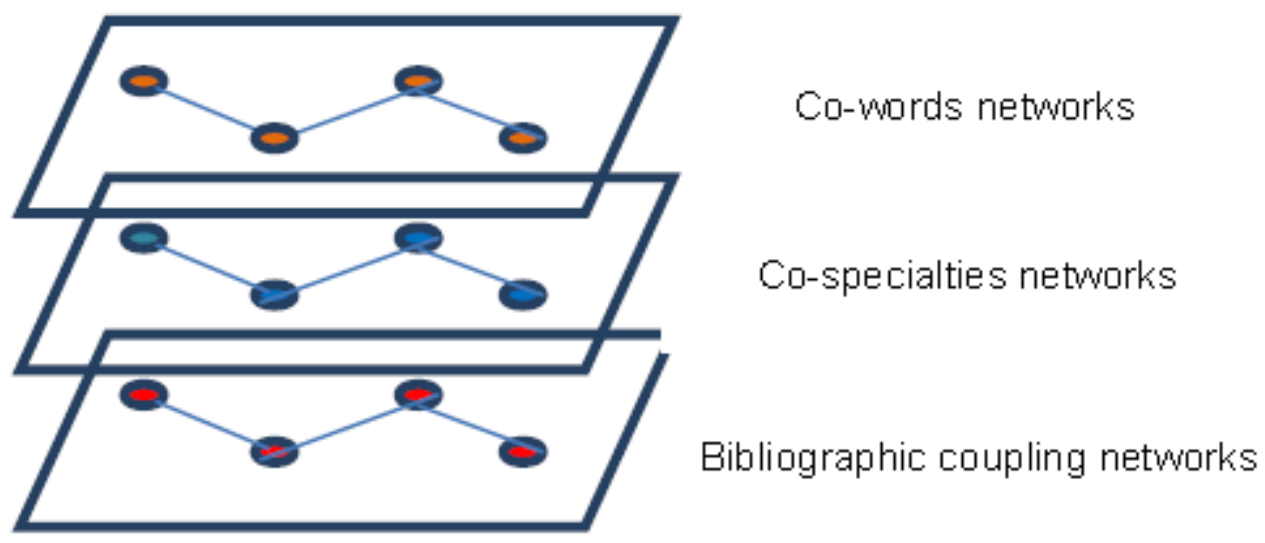

Figure 4. Communication events as multilayered networks.

Figure 4 represents a distinction in a three-dimensional space. The three planes are ordered by the same communication events and share different elements in co-presence (words are part of titles and key words in articles, specialties can be deduced from the journal knowledge area, and common bibliographic references -same for figure 3). The two vertices in the middle connect the two vertices on the edges. Together they form a possible distinction because they share elements of different kind. Literally a form is represented through aggregation.

If other distinctions are found in a set of possible messages, then a three-dimensional graph can be presented as a network of distinctions in a space. If time is considered in this network as another criterion to group vertices, then it is possible to trace a time line. Distinctions as a group of communication events can be read as trajectories of a distinction ${ }^{9}$. In other words, an emergent form can be represented as a network of events distributed in time.

Then it is possible to represent as many trajectories as it can be traced by distinctions observed: For instance (1) trajectories of scientific contributions from a possible set of messages; (2) trajectories of themes within a communities of researchers that reference common works in their articles; (3) trajectories of field strategies; (4) trajectories of science diffusion in society between others. Trajectories are distributions of communication events that build and are built at the same time by distinctions and recursions.

These are networks of meaning which map expectations and possible worlds. In this way science as a system can be described through structural concepts such as core and

\footnotetext{
${ }^{9}$ It is important to clarify that grouping communication events delimited by distinctions means that one event may also be in as many groups as loops can be found by co-presence of elements.
} 
Número 1, Noviembre 2013. No 02/04. ISSN: 2014-5993

peripheries, fragmentation, regionalization, depending on distribution of communication events in space.

\section{Methodology}

This research assumes as much cross intersection between systems and networks as possible. The methodology will employ mix network analysis methodology (graphs, sets and algebraic matrices theories) and theory of form from Baecker (2013). Using these two methodologies, the frontier between qualitative and quantitative methods is fuzzy: networks and forms need phenomenology and mathematics to build results.

First methodological procedure will be an exploration of theoretical categories through a comprehensive review of different works as following:

1) Trajectories of contributions (problematizations and solutions): co-word analysis (Eugene Garfield, 1983), Inclusion index (Callon et al, 1995), vector space (Leydesdorff, 2008), cotext analysis (Vélez Cuartas, 2012). In general, a contrast between models of text analysis is needed. This exploration will consider theories that allow to explore and to analyze large amounts of texts.

2) Formation of academic communities with different levels of strength: concept of invisible college will be explored and their developments on co-citation analysis, main path analysis (Hummon \& Doreian, 1989) and algorithmic historiography (Garfield et al, 2003; Crane, 1972; De Solla Price, 1963).

3) Description of successful field strategies to reach visibility and prestige: Precisions will be done on the work of Ramirez Ruiz (2010) based on Bourdieu's concept of Field and Scientific Collaboration from Newman MEJ, and De Nooy, W (2002) on Arts based on Field concept.

4) Variation of communication forms depending on synergies with other social systems: Leydesdorff's (2001a) works on synergies and triple helix models will be demarked on Networks of Meaning context.

This literature review will use content analysis considering meta-categories of distinction, trajectory and aggregation specifying operational categories to network analysis. 
Número 1, Noviembre 2013. No 02/04. ISSN: 2014-5993

To evidence difference between data bases, data mining has to be done starting on regional Datant Ciencia ${ }^{10}$ in contrast with ISI Thompson and Scopus. The data mining has advanced in previous research. This project only contemplates debugging.

Scientific production in Antioquia will be outlined from 2006 to 2012. This period represents important changes in practices and growth of scientific production to social sciences in Colombia. It is important to clarify that this project represents a third phase of exploration on this issue in our research group. Two previous phases tried to build a repository and present a qualitative analysis about institutional and researchers situation in Colombia. This phase contemplates to demonstrate that alternatives to visualization and trajectories visibility of social sciences arts and humanities can be built.

With data bases debugged maps on trajectories of contributions, invisible colleges, field strategies and synergies have to be made. Networks of Meaning use three kinds of main procedures: grouping algorithms, cross-intersection, and time visualization procedures. Software Pajek will be necessary to implement this kind of measures. Grouping algorithms as Louvain or VOS algorithm (Blondel et al, 2008; Newman, 2006; De Nooy, Batagelj \& Mrvar, 2012) allow visualizing aggregation. We have to remember that we are considering aggregation as co-presence of marks in communication events. Cross-intersection (De Nooy, Batagelj \& Mrvar, 2012) makes possible to specify groups juxtaposing co-presence networks.

The time visualization could be traced through partitions of communication events in publication dates. Two kinds of software can be useful to this purpose: Pajek through networks in time procedure (see some procedures from De Nooy, 2011), and Visone to visualize. Nevertheless, procedures to visualize time have to be improved to show time in a plane dimension, perhaps as a time line.

\footnotetext{
${ }^{10}$ At the Universidad de Antioquia, the Research Group Social Networks and Actors that belong to Social Science and Humanities Research Center from Faculty began to build a repository of all knowledge produced by all their faculties on social sciences, arts and humanities called Datant Ciencia. This data base has more than 4000 products that include not only journal articles and books or books chapters but also another kind of nonconventional communications to bibliometric studies as musical scores, consultancy technical reports, policy models, etc. This repository was built based on production present on national journals indexed by Publindex (governmental office which build rankings of national journals according to their quality); besides, products present on social sciences, arts and humanities research centerscentres at the Universidad de Antioquia were included too. All this information was made compatible with categories and fields available in Scopus and ISI Thompson data bases following international recommendations and rules (i.e. MARC 21 Standards).
} 
Número 1, Noviembre 2013. No 02/04. ISSN: 2014-5993

At last, Leydesdorff has developed free access software ${ }^{11}$ to process large amount of textual data from ISI Thompson and Scopus. That software can be useful to build Pajek files and facilitate information processing.

\section{Bibliografía}

Archambault E \& Lariviere V (2010). "The limits of bibliometrics for the analsysis of the social sciences and humanities literature", en World Social Science Report 2010: Knowledge Divides. Paris: UNESCO, pp. 251-255.

Baecker, D (2007). "The Network Synthesis of Social Action I: Towards a Sociological Theory of Next Society". Cybernetics and Human Knowing, Vol. 14, pp. 9-42

Baecker, D (2008). "The Network Synthesis of Social Action II: Understanding Catjects". Cybernetics and Human Knowing. Volume 15, Number 1, 2008, pp. 45-66

Baecker, D (2013). "Systemic Theories of Communication", en Cobley, P \& Schulz, PJ. (eds).Theories and Models of Communication. De Gruyter: Germany, pp. 85-100.

Blondel V, Guillaume JL, Lombiotte R, Lefebvre E (2008). "Fast unfolding of communities in large networks." J. Stat. Mech. arXiv:0803.0476 [physics.soc-ph]. P10008

Newman MEJ (2006). "Modularity and community structure in networks". J. Stat. Mech. arXiv:physics/0602124v1 [physics.data-an] 17 Feb 2006

Bourdieu, P (2001). Science de la science et reflexivité. Paris: Editions Rason d'agir.

Cantor, G (1915). Contribution to the founding of the theory of transfinite numbers. New York: Dover Publications.

Callon, Michel, Jean-Pierre Courtial y Hervé Penan (1995). Cienciometría. El estudio cuantitativo de la actividad científica: de la bibliometría a la vigilancia tecnológica. Gijón: Ediciones Trea.

Contractor, N; Monge, P (2003). Theories of Communication Networks. New York: Oxford University Press.

Crane, D (1972) Invisible colleges. Diffusion of knowledge in scientific communities. The University of Chicago Press: Chicago and London.

De Nooy, W (2002). "The dynamics of artistic prestige”, Poetics, 30 (3), pp. 147-167.

\footnotetext{
${ }^{11} \mathrm{http}: / /$ www.leydesdorff.net/software.htm
} 
Número 1, Noviembre 2013. No 02/04. ISSN: 2014-5993

De Nooy, Wouter, Andrej Mrvar y Vladimir Batagelj (2012). Exploratory Social Networks Analysis with Pajek. New York: Cambridge University Press.

De Nooy, Wouter (2011). "Networks of action and events over time. A multilevel discrete-time event history model for longitudinal network data". In Social Networks , 33(1), 31-40.

Garfield, Eugene (1983) [1979]. Citation Indexing- It's Theory and Application in Science, Technology, and Humanities. Philadelphia: ISI press.

Garfield E, Pudovkin Al, Istomin VS (2003). "Why do we need Algorithmic Historiography?", Journal of the American Society for Information Science and Technology (JASIST), 54 (5):400-412, March 2003.

Glänzel, W.; Schoepflin, U. (1999). "A bibliometric study of reference literatura in the sciences and social sciences". Inf. Process. Manage., 35 (1), 31-44.

Hummon N.P., Doreian P (1989). "Connectivity in a citation network: The Development of DNA theory", Social Networks, 11, 36-63

Knorr-Cetina, Karin (2005). La Fabricación del Conocimiento: Un Ensayo sobre el Carácter Constructivista y Contextual de la Ciencia. Buenos Aires: Universidad Nacional del Quilmas Editorial.

Latour, B (1999). Pandora's hope: essays on the reality of science studies. Harvard University Press, Cambridge Mass., USA, 1999.

Leydesdorff, Loet (2001). The Challenge of Scientometrics: The Development, Measurement, and Self-Organization of Scientific Comunications. uPublish.com: Universal Publishers. USA

Leydesdorff, Loet (2001a). A Sociological Theory of Communication: The Organization of the Knowledge-Based Society. u- Publish.com: Universal Publishers.

Leydesdorff, Loet (2008). "The Communication of Information, Meaning and Knowledge: relational versus vectorial topologies”. Presentación en PowerPoint: Seminar Communication networks on the web. Quantitative Methods in the Social Sciences 2, Sponsored by the European Science Foundation. Diciembre 18 y 19, Amsterdam (Holanda)

Luhmann, N (1992). Sistemas sociales: Lineamientos para una teoría general [Soziale Systeme: Grundisse einer Allgemeinen Theorie]. Rubí: Anthropos; México: UIA; Bogotá: CEJA.

Luhmann, N (1996). La ciencia de la sociedad [Wissenschaft der Gesellschaft]. México: UIA. 
Número 1, Noviembre 2013. No 02/04. ISSN: 2014-5993

Luhmann, N (1997). Observaciones de la Modernidad [Beobachtungen der Moderne]. Buenos Aires: Paidós.

Luhmann, Niklas (1995). Las ciencias modernas y la fenomenología. Manuscript from Conferencia dictada en el auditorio del Ayuntamiento de Viena el 25 de mayo de 1995. Translated by: Javier Torres Nafarrate.

Merton, RK (1979). The Sociology of Science: Theoretical and Empirical Investigations. Chicago: University Of Chicago Press.

Nadel, SF (1957). The theory of social structure. London: Cohen \& West.

Nieto Galan, A (2011). Los públicos de la ciencia: Expertos y profanos a través de la historia. Madrid: Marcial Pons.

Ramírez Ruiz, L (2010). "Campo científico y redes de coautoría en la psiquiatría; la producción científica psiquiátrica mexicana sobre el trastorno de la personalidad", Redes Revista hispana para el análisis de redes sociales, 19 (2), pp. 20 - 39.

Rodríguez Yunta, L. (2010). "Las revistas iberoamericanas en Web of Science y Scopus: visibilidad internacional e indicadores de calidad (en línea)". UNAM, Centro Universitario de Investigaciones Bibliotecológicas. Disponible en: http://hdl.handle.net/10261/23811 [consulta el 24/02/2012]

Rogers EM y Kincaid L (1981). Communication Networks: Toward a New Paradigm for Research. Nueva York: The Free Press.

Spencer-Brown G (1977) [1972]. Laws of Form. New York: The Julian Press.

Varela, F (1979). Principles of Biological Autonomy. New York: Elsevier North Holland

Vélez Cuartas, G; Ramírez Ruiz, L; Aristizábal Botero, CA (2013). "El conocimiento científico y tecnológico disponible en el departamento de Antioquia 1990-2010”. Research final report. Universidad de Antioquia.

Vélez Cuartas, G (2012). "Las Redes de Sentido como Modelo de Observación para la Ciencia: Luhmann desde un punto de vista estructural. [Meaning Networks as Model to Observe Science: Luhmann from a Structural Point of View]", en Estrada Saavedra, M y Millán, R. La Teoría de los Sistemas de Niklas Luhmann a Prueba. [Systems Theory of Niklas Luhmann Proof]. México: UNAM, COLMEX, pp. 219-274. 


\section{GRAFO Working Papers}

Número 1, Noviembre 2013. No 02/04. ISSN: 2014-5993

Wellman, B (1988). "Structural analysis: from method and metaphor to theory and substance", en Wellman, B; Berkowitz, S. Social structures: a network approach. New York: Cambridge University Press, pp. 19-61.

White H, Fuhse J, Thiemann M, Buchholz L (2007). "Networks and Meaning: Styles and Switchings". Soziale Systeme, 13, Heft 1+2, pp. 543-555

White, H (2008). Identity and Control: How Social Formations Emerge? New Jersey: Princeton University Press. 